LETTER TO JMG

\title{
Missense mutations of ACTAl cause dominant congenital myopathy with cores
}

\author{
A M Kaindl, F Rüschendorf, S Krause, H-H Goebel, K Koehler, C Becker, D Pongratz, J Müller- \\ Höcker, P Nürnberg, G Stoltenburg-Didinger, H Lochmüller, A Huebner
}

J Med Genet 2004;41:842-848. doi: 10.1136/jimg.2004.020271

C ongenital myopathies (CM) are neuromuscular disorders classified by characteristic histopathological findings in muscle fibers. Areas devoid of oxidative enzyme activity (core lesions) are pathological hallmarks of autosomal dominant or recessive central core disease (CCD; MIM 117000) and multiminicore disease (MmD; MIM 255320). While large and solitary cores in the center and along the entire length of muscle fibers are considered typical for CCD and multiple smaller cores within muscle fibers define $\mathrm{MmD}$, this classic histological distinction is complicated by the marked histological variability of core lesions. ${ }^{1}$ Minicores and central cores have been detected concomitantly as well as separately in successive muscle biopsy specimens of single patients and in myofibers of different affected family members. ${ }^{1-4}$ So far, mutations in three gene loci have been associated with core myopathies: ryanodine receptor-1 gene (RYRI; MIM 180901) in both CCD and MmD, selenoprotein N-1 gene (SEPNI; MIM 606210) in $\mathrm{MmD}$, and myosin heavy chain-7 gene (MYH7; MIM 160760) in CCD. ${ }^{5-7}$

The increased number of identified genetic defects in patients with thoroughly characterised CM phenotypes has disclosed both marked phenotype and genotype variability and considerable disease overlap. The finding of cores together with rod-like lesions in muscle biopsy specimens of patients with RYRI mutations and skeletal muscle alphaactin gene (ACTAI; MIM 102610) mutations and in families showing linkage to chromosome 15q21-q23 indicate a phenotype overlap of core diseases and nemaline myopathy (MIM 256030)..$^{8-14}$ Likewise, the concurrent occurrence of cores and fingerprint bodies suggests an overlap with fingerprint body myopathy (MIM 305550). ${ }^{15}$ These findings and an absence of mutations in established gene loci in patients with clinical and histological hallmarks of core myopathy promise further genetic heterogeneity.

ACTAl mutations are known to cause three congenital myopathies: nemaline myopathy, actin myopathy (MIM 102610), and intranuclear rod myopathy. ${ }^{16}$ Here, we are the first to report on ACTAl mutations which cause a fourth type of $\mathrm{CM}$ in two families, an autosomal dominant congenital myopathy with cores.

\section{METHODS}

\section{Patients}

We studied 14 patients and 27 unaffected relatives of two unrelated families of German (family 1 ) and Chinese (family 2) descent after written informed consent was obtained. The diagnosis of core myopathy was established on the basis of clinical and histopathological criteria. ${ }^{17}$ Analysis of muscle specimens was performed in five patients (patients III:9, III:12, and IV:11 in family 1 , and patients II:2 and III:2 in family 2; fig 1 ).

\section{Key points}

- Central core and minicore diseases are clinically and genetically heterogeneous, autosomal dominant or recessive congenital myopathies characterised by muscle weakness and areas devoid of oxidative activity (cores) within myofibers. So far, mutations in the ryanodine receptor-1 gene (RYR 1$)$, the selenoprotein $\mathrm{N}-1$ gene (SEPN1), and the myosin heavy chain-7 (MYH7) gene have been identified as a cause of core myopathies.

- Here, we are the first to report on an autosomal dominant "core only" myopathy caused by missense mutations of the skeletal muscle alpha-actin gene (ACTA1) in two families.

- Patients of both families showed a rather mild and nonprogressive course of skeletal muscle weakness. Interestingly, the myopathy was accompanied by adult onset hypertrophic cardiomyopathy and respiratory failure in one family. Histologically, cores were detected in the muscle fibers of at least one patient in each family, while nemaline bodies or rods and actin filament accumulation were absent.

- These findings establish ACTA1 mutations as a new cause of dominant congenital myopathy with cores and describe a new clinicopathological phenotype for ACTA1.

\section{Linkage analysis}

Genomic DNA was isolated from peripheral blood lymphocytes according to standard procedures. Microsatellite analysis was performed with sequence specific forward and reverse primers and universal fluorescent labeled M13 labelled primers ${ }^{18}$ by standard semi-automated methods using an ABI 3100 Genetic Analyzer (Applied Biosystems, Foster City, CA, USA). We confirmed the order of microsatellite markers flanking RYR1, SEPN1, MYH7, and ACTAl in published human linkage maps (Ensembl Genome Browser, Human Genome Browser Gateway, and Entrez Genome View) and amplified four to six markers for each gene locus.

\section{Genome-wide linkage scan}

We performed genome-wide linkage analysis using the early access GeneChip Human Mapping 10K Array and Assay Kit from Affymetrix (Santa Clara, CA, USA) with 11560 single

Abbreviations: ACTC, cardiac alpha-actin gene; ACTAl, skeletal muscle alpha-actin gene; $C C D$, central core disease; $C M$, congenital myopathies; EM, electron microscopy; $M m D$, multiminicore disease; $M Y H 7$, myosin heavy chain-7 gene; RYR 1, ryanodine receptor-1 gene; SEPN1, selenoprotein $\mathrm{N}-1$ gene 


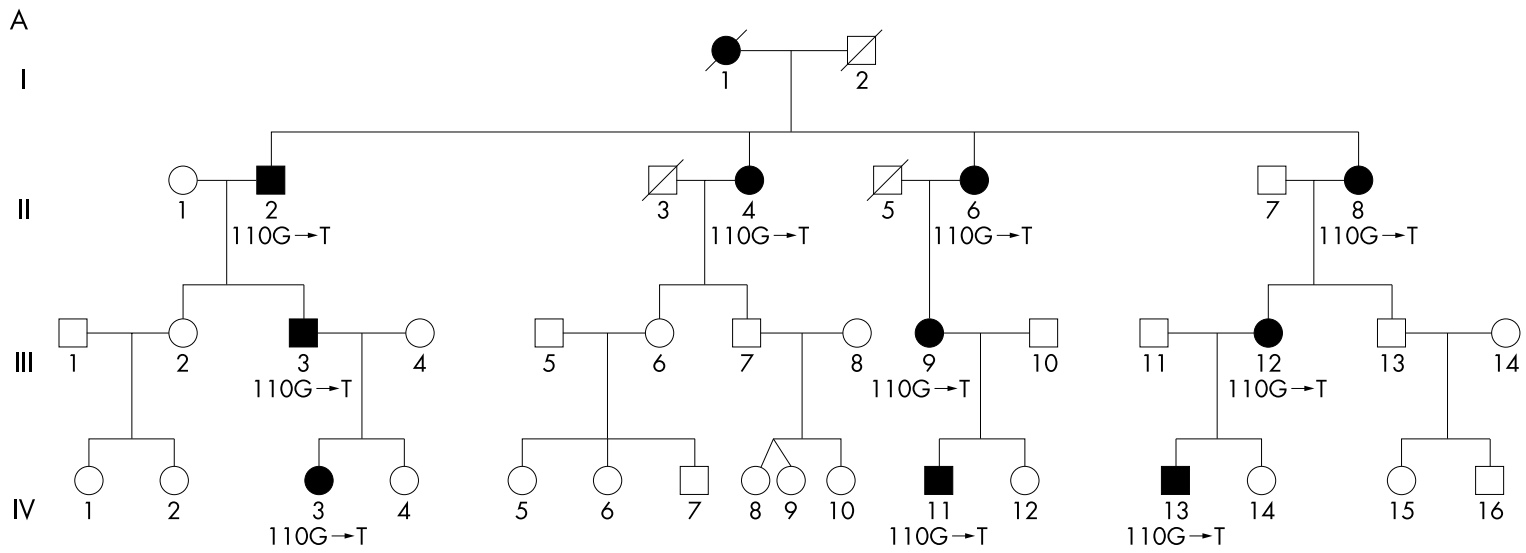

B

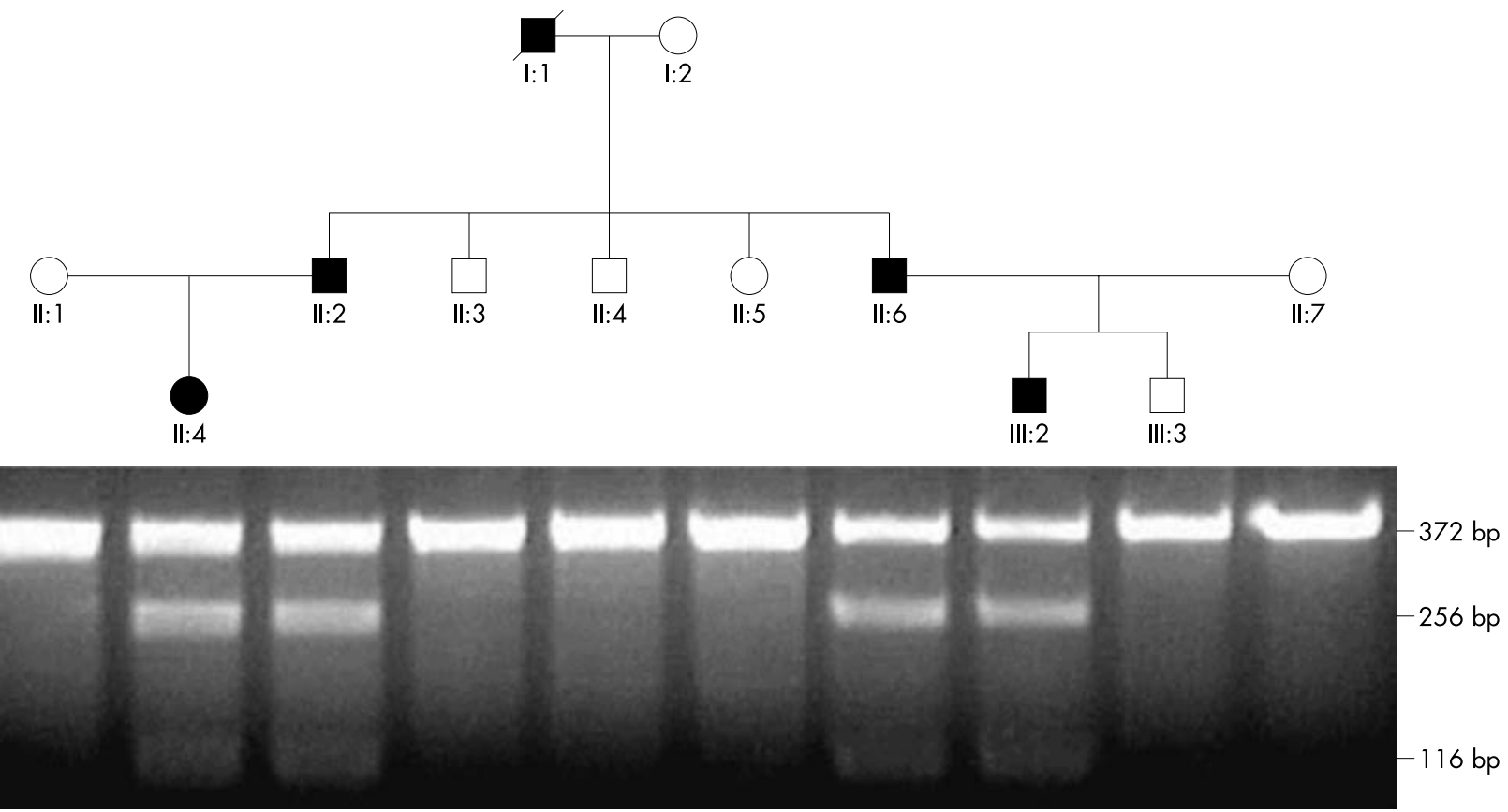

Figure 1 Pedigrees of two families with autosomal dominant core disease and segregation of the $110 G \rightarrow T(A ;$ family 1$)$ and $1110 A \rightarrow C$ (B; family 2$)$ missense mutations of ACTA1 on chromosome 1q42. ACTA1 mutations were not found in unaffected family members. (B) The heterozygous mutation detected in all affected members of family 2 introduces a new Paul site. PCR fragments of the mutated allele are cut into two fragments of 256 and $116 \mathrm{bp}$, whereas the wild type sequence remains uncut ( $372 \mathrm{bp})$.

nucleotide polymorphisms (SNPs). ${ }^{19}$ For quality control and data conversion, a computer program was written. We verified the relationship of family members with the GRR program and the gender of individuals through the analysis of X linked markers for heterozygous genotypes. ${ }^{20}$ PedCheck was used for detection of Mendelian errors. ${ }^{21}$ With Merlin, we identified unlikely genotypes and subsequently removed all erroneous genotypes from the data set. ${ }^{22}$ We performed parametric linkage analysis with a modified version of GeneHunter. ${ }^{23} 24$

\section{Sequencing analysis}

All six protein encoding exons of ACTAl (GenBank accession number NM_001100) and adjacent exon-intron boundaries were sequenced in patient III:9 (family 1), patient II:2 (family 2), and one control. We amplified and sequenced exons 2 and 7 in all members of families 1 and 2, respectively, and also in 50 controls. Primer sequences designed for amplification of exons 2 and 7 were $5^{\prime}$-CCCTGCCGCTGA GACTTCTG-3' (forward), 5' -GCAGCCTGACCTGGTGTCGG-3' (reverse) and 5'-AGCACCATGAAGATCAAGG-3' (forward),
5'-CTGTGTCAGTTTACGATGGCAGC-3' (reverse), respectively. PCR cycling conditions and further primer sequences used for linkage analysis and sequencing are available from the authors on request.

\section{Restriction fragment analysis}

To confirm the $1110 \mathrm{~A} \rightarrow \mathrm{C}$ mutation that creates a novel PauI site in family 2, a 372 bp fragment containing ACTAl exon 7 was amplified by PCR using the following primer set: 5'AGCACCATGAAGATCAAGG-3' (forward) and 5'-CTGTGT CAGTTTACGATGGCAGC-3' (reverse). PauI restriction digest of the mutated allele releases two fragments of 256 and $116 \mathrm{bp}$, whereas the wild type allele remains uncut.

\section{RESULTS}

\section{Clinical and histological features}

All patients reported a clinical onset of proximal or generalised muscle weakness in early childhood. Disease severity showed a slight intra- and interfamilial variation with usually mild and non-progressive symptoms such as moderate muscle weakness with delayed motor milestones, 


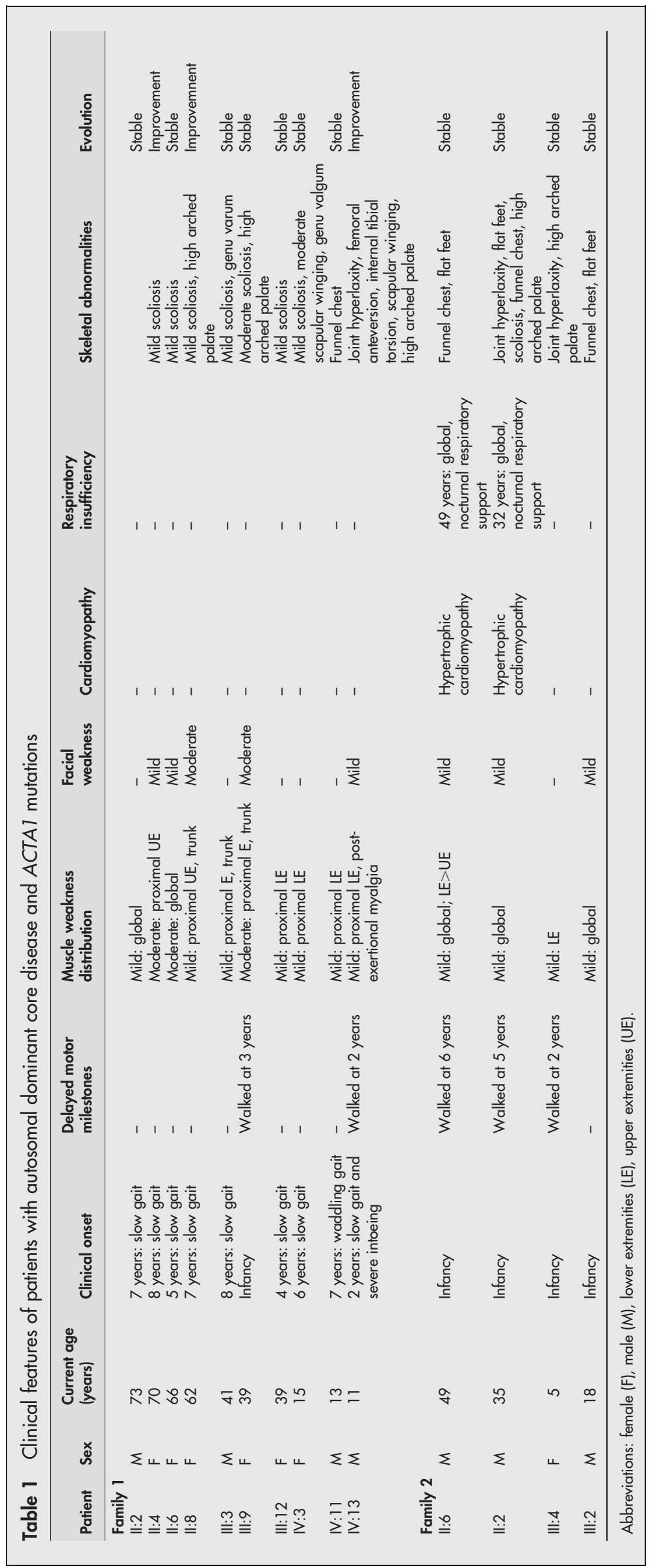


difficulties climbing stairs and running, facial weakness, slowness of movements, post-exertional myalgia in childhood, and skeletal abnormalities (fig 2; table 1). Index patient IV:11 of family 1 presented at the age of 7 years with a non-progressive, mild, and proximal muscle weakness (waddling gait, difficulties getting up from supine position; fig 2A). Also, he exhibited a funnel chest, hyperlordosis of his lumbar spine, and distal joint hyperlaxity on physical examination. His mother (III:9) was affected more severely; she had delayed motor milestones and moderate proximal muscle and facial weakness. Similar to other patients of family 1 , she complained of slowness in movements. She was unable to run, but could walk for hours.

Two patients of family 2 (II:2 and II:6; fig 1B) developed adult onset hypertrophic cardiomyopathy and respiratory insufficiency. Patient II:2, currently 35 years of age, had delayed motor milestones and started walking at the age of 5 years. He was never able to run, but worked full time in a restaurant. He did not seek medical assistance until the age of 32 years, when a global respiratory insufficiency developed that now requires nocturnal ventilation. On examination, he showed mild, symmetrical, distal, and proximal muscular weakness, a high arched palate, planus feet, a funnel chest, marked scoliosis, and distal joint laxity. CK levels were normal. Hypertrophic cardiomyopathy was detected by echocardiography. His older brother (II:6), now 49 years of age, shows a similar clinical picture with a milder clinical course that required nocturnal ventilation only recently. Cardiomyopathy was detected by echocardiography at age 47 , that is, 2 years before he developed clinical signs of respiratory insufficiency. Initially, only thickening of the septum and the left ventricular wall was seen. Recently, additional signs of right ventricular dilatation and heart failure were detected that improved under ventilation.

Histologically and ultrastructurally, myopathic changes and core lesions were detected in skeletal muscle biopsy specimens of both families; nemaline rods were absent and there was no accumulation of actin filaments. ATPase staining and staining with antibodies to slow myosin demonstrated type I fiber predominance in all patients. A comparison of core lesions in biopsy specimens from members of both families revealed differences in size, number, and appearence. In family 1 , primarily singular core lesions were found in muscle specimens of two patients (quadriceps femoris muscle). Cores were unstructured, poorly circumscribed, central, or eccentric: they were rather broad but did not run along the entire long axis of muscle fibers and are thus typical neither of CCD nor of MmD (fig 3). Immunocytochemical staining of muscle biopsy sections from patients and controls showed a normal uniform honeycomb staining pattern of actin. In family 2, two biopsies of patient II:2 were taken at the age of 32 (biceps brachii muscle) and 33 years (lateral gastrocnemius muscle), and one biopsy specimen of patient III:2 was taken at the age of 14 years (quadriceps femoris muscle). Histologically, cores were detected in both biopsy samples of patient II:2. Similarly to family 1, core lesions were poorly circumscribed, both central and eccentric. In contrast to family l, cores were very small, and multiple cores occurred in a single muscle fiber. Ultrastructurally, these minicore-like lesions appeared as circular zones containing contractile filaments, but were devoid of mitochondria (fig 3). Interestingly, myopathologic findings in the muscle biopsy specimen of patient III:2 were unspecific and cores were not found. A slight preponderance of type I fibers was noted on ATPase stains, but the sizes of type I and type II fibers were within the normal range (data not shown).

\section{Genetic results}

Linkage to the three core disease loci RYRI, MYH7, and SEPNI reported at the time of our study was excluded in both families. Therefore, we performed genome-wide linkage analysis in family 1 using GeneChip Human Mapping 10K Array and Assay Kit from Affymetrix. Genotyping was performed in 10 affected and six unaffected members of family 1 , and a maximum multi-point LOD score of 3.31 was calculated around SNP rs54108 on chromosome 1q42. We defined a critical disease interval of about $4.6 \mathrm{cM}$, equivalent to approximately $7 \mathrm{Mbp}$, by haplotype reconstruction. ACTAl was selected as the most promising candidate gene considering the following: (i) alpha-actin interacts with a variety of proteins including myosin heavy chain, which previously has
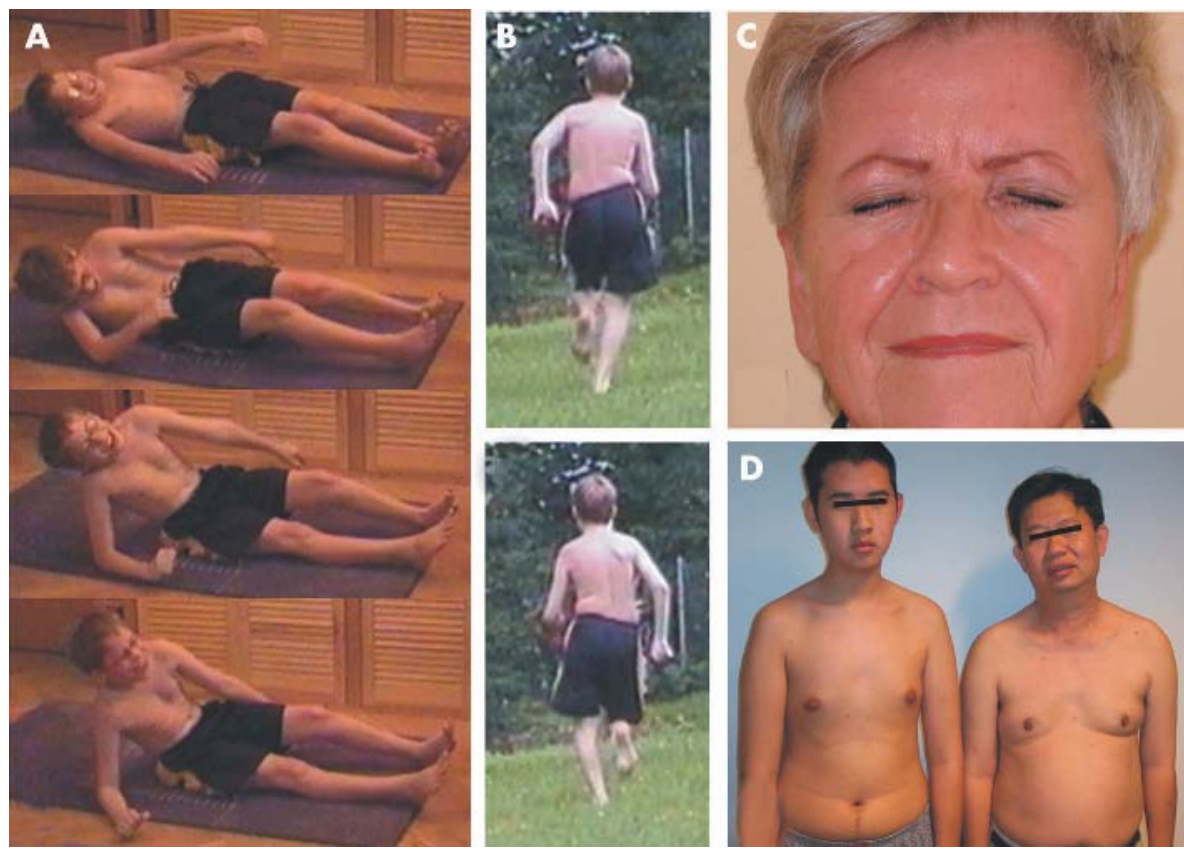

Figure 2 Patients with ACTAl core myopathy. Patient IV: 11 of family 1 presented at the age of 7 years with symptoms of a mild proximal muscle weakness with difficulties getting up from a supine position $(A)$ and a waddling gait upon running (B). His affected relative II:8 had normal facial expression but was unable to bury her eyelashes upon maximal eye closure (C). The two patients II: 6 and III:3 of family 2 exhibited mild global muscle weakness since infancy, had funnel chests, and planus feet (D). Reproduced with permission. 


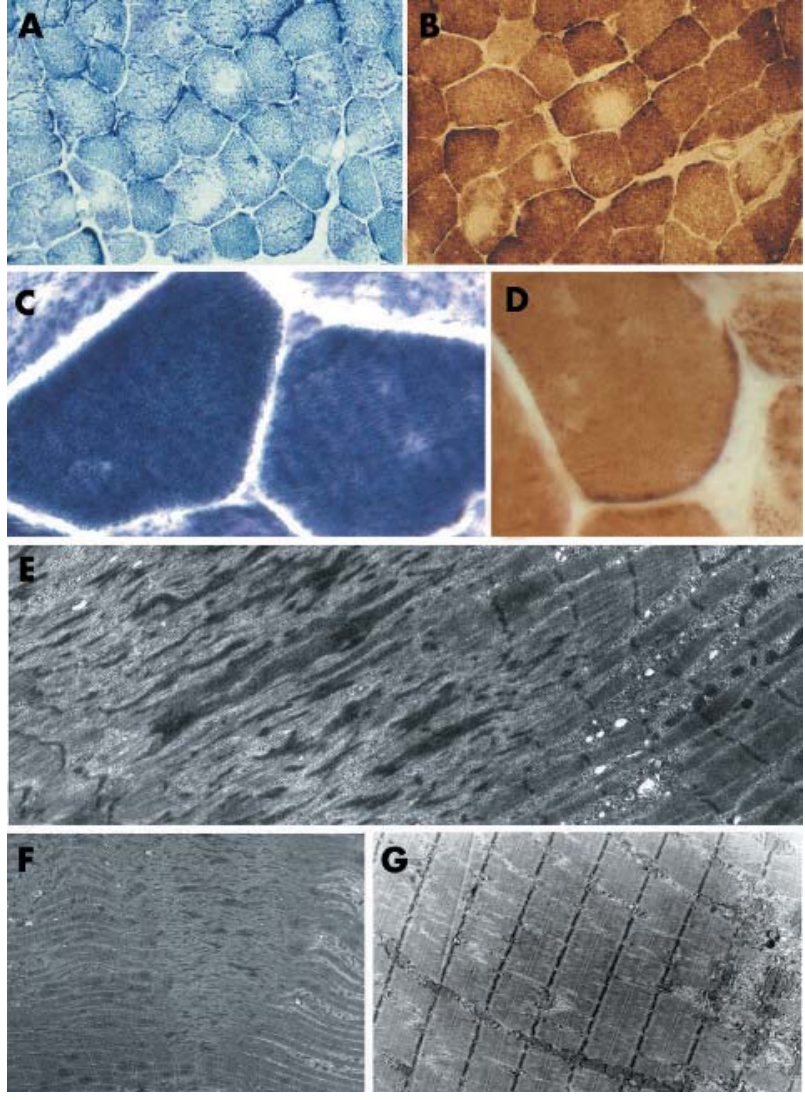

Figure 3 Core lesions in patients with ACTA 1 core myopathy. Muscle biopsies were taken at the ages 9 (B; patient III: 12 of family 1), 10 (A, E, F; patient IV: 11 of family I), and 33 years (C, D, G; patient II: 2 of family 2). Core lesions in biopsy specimens of both families differed in size, number, and appearance. Primarily singular poorly circumscribed cores presented as large centrally and excentrically located defects in NADHTR $(A$; magnification $\times 40)$ and COX preparation $(B$; magnification $\times 40)$ in specimens of family 1 . Electron microscopy (EM) of longitudinal sections at $1100 \times(\mathrm{F})$ and $3000 \times(\mathrm{E})$ magnification showed destruction of the myofibrillar structure within these lesions (unstructured cores) surrounded by normal sarcomeres. These cores do not run along the entire long axes of muscle fibers and may therefore not be encountered in the majority of fibers in a single cross section. In muscle specimens of family 2, cores were significantly smaller and more frequent in NADH-TR $(C$; magnification $\times 400$ ) and COX preparation ( $D$; magnification $\times 400)$. On EM, these minicore-like lesions lacked mitochondria and showed Z disk lesions (G; magnification $\times 3300$ ). Myosin ATPase preparation at $\mathrm{pH} 9.6$ showed marked type 1 muscle fiber predominance in all patients.

been associated with core disease ${ }^{7}$; (ii) mutations in ACTAl can cause congenital myopathies including nemaline myopathy with core-like lesions ${ }^{11}$; (iii) the concomitant finding of core- and rod-like lesions in a single muscle specimen ${ }^{10} 1113$ indicates a phenotype overlap of core disease and actinopathy (nemaline myopathy). In all affected members of family 1 we identified the heterozygous transversion $1 \mathrm{loG} \rightarrow \mathrm{T}$ (GenBank accession number NM 001100) predicted to result in a change from aspartic acid to tyrosine at position 1 of mature alpha-actin (DIY; fig 4). We subsequently demonstrated linkage to ACTAI for the second family using selected markers that flank the gene locus (data not shown). In family 2, we detected the heterozygous missense mutation $1110 \mathrm{~A} \rightarrow \mathrm{C}$ in all affected patients (E334A; fig 4). The segregation of each ACTAl mutation with the disease in one family, their absence in both the unaffected family members and 50 control individuals, as well as the location of the two mutations at highly conserved amino acid positions (fig 4) strongly suggest that these mutations cause the clinical phenotype of autosomal dominant core myopathy. Neither of the two mutations has been reported previously.

\section{DISCUSSION}

In this study, we have identified mutations of ACTAI as a cause of autosomal dominant core myopathy in two families of different ethnic origin. So far, ACTAl mutations have been reported to cause three forms of congenital myopathy (nemaline myopathy, intranuclear rod myopathy, actin myopathy), but cores have not been described as exclusive histopathological features in these disorders. Conversely, "core only" myopathies have been shown to be caused by mutations in three different genes (RYRI, SEPNI, MYH7), but not in ACTAl.

Among patients with ACTAl mutations, the severe form of nemaline myopathy with early onset muscle weakness, rapid course, and respiratory insufficiency is most frequently reported. A benign phenotype similar to that found in our patients is rare, but has been reported. ${ }^{11}{ }^{14}$ Similarly, the slowness of movements of our patients with core myopathy is an unusual feature of ACTAl diseases, but has been described in single patients with core rod myopathy and RYRl mutations or linkage to chromosome 15q21-q23. ${ }^{13} 14$ Since, to the best of our knowledge, cardiomyopathies have not been reported in ACTAl myopathies, the hypertrophic cardiomyopathy detected in family 2 is of particular interest. We cannot exclude that the cardiomyopathy detected in patient II:2 is secondary to a longstanding and impaired respiratory function, since his heart function was first assessed after respiratory insufficiency had developed. However, echocardiography of patient II:6 showed signs of cardiomyopathy 2 years prior to respiratory insufficiency. Both the left ventricle and the septum were affected at this time, a finding which is not expected for cardiomyopathies due to respiratory failure. Moreover, ACTAl accounts for approximately $20 \%$ of the total amount of actin in healthy human myocardium. ${ }^{25}$ Mutations in the cardiac alpha-actin gene (ACTC; MIM 102540), which encodes the predominant actin isoform of mature myocytes $(\sim 80 \%)$, can cause familial hypertrophic and dilated cardiomyopathy. ${ }^{25-27}$ Thus, even though cardiomyopathy is not an established feature of ACTAl myopathies and one actin isoform has been suggested to partially compensate for the other, ${ }^{14}$ ACTAl mutations could affect cardiac and skeletal muscle simultaneously similarly to mutations in other genes causing nemaline myopathy or core disease. Histopathological studies of cardiac muscle, if they become available, may clarify this finding.

The histopathological phenotype of skeletal muscle biopsy specimens of patients with dominant core myopathy caused by ACTAl mutations is variable, but clearly different from previously described actinopathies. It combines characteristics suggestive of atypical central core disease with those found in atypical minicore disease and shows similarities to core-like areas reported in addition to typical nemaline rods for patients with ACTAl mutations or linkage to chromosome 15q21-23. ${ }^{11}{ }^{13}$ Moreover, cores were absent in the quadriceps femoris muscle of one patient of family 2 biopsied at 14 years of age. Since this biopsy showed only rather unspecific features, the given molecular diagnosis probably would have been missed in a sporadic case. Thus, mutations in the ACTAI gene should be considered in patients with a congenital myopathy and an unspecific histopathological phenotype.

Neither of the ACTAl mutations reported in this study have been described previously in humans or mice. Therefore, we can only speculate about the functional consequences of these mutations. Interestingly, the mutation detected in family $1(110 \mathrm{G}>\mathrm{T})$ causes an amino acid exchange of the 
A

Patient

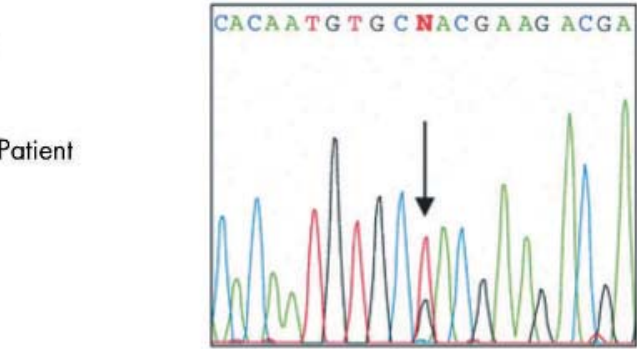

CACAA TG T GC GACG A AG ACGA

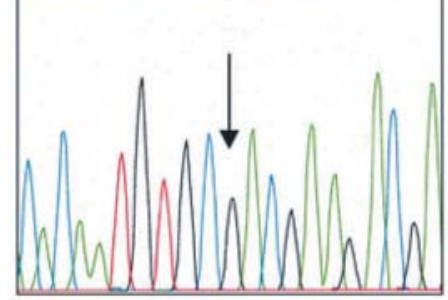

B

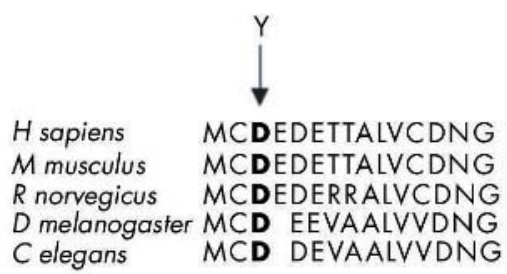

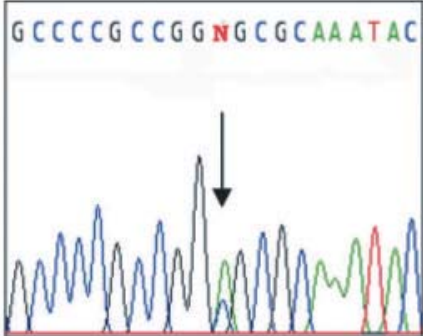

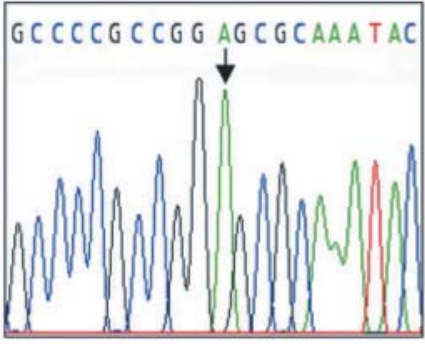

Figure 4 Mutations in ACTA 1 in patients with autosomal dominant core disease. (A) Heterozygous $G \rightarrow T$ transversion at nucleotide position 110 in exon 2 and heterozygous $A \rightarrow T$ transversion at nucleotide position 1110 in exon 7 of ACTAl are demonstrated in affected patients. These mutations are absent from DNA samples of control individuals. (B) Alignment of alpha-actin protein regions of five different species. Both mutations cause the exchange of a highly conserved amino acid (DIY; E334A; GenBank accession number NM_001100). Sites of mutation are indicated by arrows. first amino acid of the mature actin protein (DIY). In humans, alpha-actin precursor protein is transformed into mature alpha-actin by co- and posttranslational acetylation and cleavage of the first two amino acids methionine and cysteine and subsequent acetylation of the then initial residue aspartic acid. ${ }^{28}$ The highly conserved $\mathrm{NH}_{2}$-terminal amino acid sequence is regarded as essential for this unique processing procedure..$^{29}$ So far, the impact of amino acid changes in this part of the protein could be exclusively inferred from studies that include site directed mutagenesis, ${ }^{31}$ antibodies directed towards the first amino acids of actin, ${ }^{32}$ and chemical crosslinking experiments. ${ }^{33}$ In vitro inhibition of actin acetylation leads to the accumulation of the actin precursor in Drosophila. ${ }^{34}$ Moreover, the interaction of alphaactin with other proteins may be disturbed by the missense mutation DIY, since the $\mathrm{NH}_{2}$ terminus is considered to be a major binding site for interacting proteins. ${ }^{35}$ The binding of myosin heads affects the generation of force as demonstrated in studies using $\mathrm{NH}_{2}$-terminal site directed mutagenesis of Dictyostelium actin. ${ }^{36}$

The mutation detected in family $2(1110 \mathrm{~A} \rightarrow \mathrm{C})$ causes an amino acid exchange at position 334 of the mature protein (E334A). Previously, a mutation affecting position 336 of alpha-actin has been described in intranuclear rod myopathy. This residue lies within the hinge and forms part of the nucleotide binding pocket. ${ }^{16}$ Accordingly, E334A may also interfere with nucleotide binding and exchange either directly or indirectly. These effects and others including protein stability, polymerisation, and degradation can reduce force generation during muscle contraction and thus contribute to the phenotype of ACTAl core myopathy.

The description of ACTAl core myopathy expands the phenotype spectrum of actinopathies and adds to the genetic heterogeneity of core myopathies. The genetic and histomorphological overlap between core disease and nemaline myopathy highlights the fact that core lesions are not pathognomonic of a specific congenital myopathy. The mechanisms through which mutations alternatively cause CCD, MmD, nemaline myopathy, actin myopathy, or intranuclear rod myopathy remain to be identified.

\section{ACKNOWLEDGEMENTS}

The authors thank the patients and their families for participation in this study and acknowledge the help and critical comments of Petra Mitzscherling, Kerstin Neubert, Mia Hovmöller, Lars Edström, and Christoph Hübner. AMK, AH, DP, and HL are members of the German Network on Muscular Dystrophies (MD-NET, 01GM0302).

\section{ELECTRONIC-DATABASE INFORMATION}

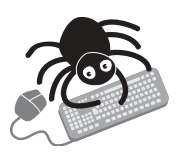

Electronic-database information is as follows: Ensembl Genome Browser: www.ensembl.org; Human Genome Browser Gateway: http://www. genome.ucsc.edu/cgi-bin/hgGateway; Entrez Genome View: http://www.ncbi.nlm.nih.gov/ mapview/

\section{Authors' affiliations}

A M Kaindl, K Koehler, A Huebner, Children's Hospital, Technical University Dresden, Dresden, Germany

A M Kaindl, Department of Neuropediatrics, Charité, University Medical School Berlin, Berlin, Germany

P Nürnberg, Institute of Medical Genetics, Charité, University Medical School Berlin, Berlin, Germany

G Stoltenburg-Didinger, Institute of Neuropathology, Charité, University Medical School Berlin, Berlin, Germany

S Krause, D Pongratz, H Lochmüller, Department of Neurology, Friedrich-Baur Institute, and Gene Center, Ludwig-MaximiliansUniversity, Munich, Germany

H-H Goebel, Department of Neuropathology, Johannes Gutenberg University of Mainz, Mainz, Germany 
F Rüschendorf, C Becker, P Nürnberg, Molecular Genetics and Gene Mapping Center, Max-Delbrueck-Center for Molecular Medicine, Berlin, Germany

J Müller-Höcker, Institute of Pathology, Ludwig-Maximilians-University, Munich, Germany

This work was supported by the German Ministry of Education and Research (BMBF, Bonn, Germany), the Myositis Association (Harrisonburg, VA, USA), and the MeDDrive program (Technical University Dresden, Germany). FR, CB, and PN are supported by the German Genome Research Network (NGFN).

Conflict of interest: none declared.

Correspondence to: Angela M. Kaindl, Department of Neuropediatrics, Charité, University Medical School, Augustenburger Platz 1, D-13353 Berlin, Germany; angela.kaindl@charite.de

Revised version received 13 April 2004

Accepted for publication 20 April 2004

\section{REFERENCES}

1 Goebel HH. Congenital myopathies at their molecular dawning. Muscle Nerve 2003:27:527-48

2 Ferreiro A, Monnier N, Romero NB, Leroy JP, Bonnemann C, Haenggeli CA, Straub V, Voss WD, Nivoche $Y$, Jungbluth $H$, Lemainque A, Voit $T$, Lunardi J, Fardeau M, Guicheney P. A recessive form of central core disease, transiently presenting as multi-minicore disease, is associated with a homozygous mutation in the ryanodine receptor type 1 gene. Ann Neurol 2002;51:750-9.

3 Sewry CA, Muller C, Davis M, Dwyer JS, Dove J, Evans G, Schroder R, Furst D Helliwell T, Laing N, Quinlivan RC. The spectrum of pathology in central core disease. Neuromuscul Disord 2002;12:930-8.

4 Jungbluth H, Sewry CA, Muntoni F. What's new in neuromuscular disorders? The congenital myopathies. Eur J Paediatr Neurol 2003;7:23-30.

5 Zhang Y, Chen HS, Khanna VK, De Leon S, Phillips MS, Schappert K, Britt BA, Browell AK, MacLennan DH. A mutation in the human ryanodine receptor gene associated with central core disease. Nat Genet 1993:5:46-50.

6 Ferreiro A, Quijano-Roy S, Pichereau C, Moghadaszadeh B, Goemans N, Bonnemann C, Jungbluth $\mathrm{H}$, Straub V, Villanova M, Leroy JP, Romero NB, Martin JJ, Muntoni F, Voit T, Estournet B, Richard P, Fardeau M, Guicheney P. Mutations of the selenoprotein $\mathrm{N}$ gene, which is implicated in rigid spine muscular dystrophy, cause the classical phenotype of multiminicore disease: reassessing the nosology of early-onset myopathies. Am J Hum Genet 2002;71:739-49

7 Fananapazir L, Dalakas MC, Cyran F, Cohn G, Epstein ND. Missense mutations in the beta-myosin heavy-chain gene cause central core disease in hypertrophic cardiomyopathy. Proc Natl Acad Sci U S A 1993:90:3993-7.

8 Davis MR, Haan E, Jungbluth $H$, Sewry C, North K, Muntoni F, Kuntzer T, Lamont P, Bankier A, Tomlinson P, Sanchez A, Walsh P, Nagarajan L, Oley C, Colley A, Gedeon A, Quinlivan R, Dixon J, James D, Muller CR, Laing NG. Principal mutation hotspot for central core disease and related myopathies in the C-terminal transmembrane region of the RYR1 gene. Neuromuscul Disord 2003; 13:151-7

9 Monnier N, Romero NB, Lerale J, Nivoche Y, Qi D, MacLennan DH, Fardeau $M$, Lunardi J. An autosomal dominant congenital myopathy with cores and rods is associated with a neomutation in the RYRl gene encoding the skeletal muscle ryanodine receptor. Hum Mol Genet 2000;9:2599-608.

10 Scacheri PC, Hoffman EP, Fratkin JD, Semino-Mora C, Senchak A, Davis MR, Laing NG, Vedanarayanan V, Subramony SH. A novel ryanodine receptor gene mutation causing both cores and rods in congenital myopathy. Neurology 2000;55:1689-96.

11 Jungbluth $\mathrm{H}$, Sewry CA, Brown SC, Nowak KJ, Laing NG, WallgrenPettersson C, Pelin K, Manzur AY, Mercuri E, Dubowitz V, Muntoni F. Mild phenotype of nemaline myopathy with sleep hypoventilation due to a mutation in the skeletal muscle alpha-actin (ACTA1) gene. Neuromuscul Disord $2001 ; 11: 35-40$

12 Bruno C, Minetti C. Congenital myopathies. Curr Neurol Neurosci Rep 2004;4:68-73

13 Gommans IM, Davis $M$, Saar K, Lammens M, Mastaglia F, Lamont $P$, van Duijnhoven $G$, ter Laak HJ, Reis A, Vogels OJ, Laing N, van Engelen BG,
Kremer $\mathrm{H}$. A locus on chromosome $15 \mathrm{q}$ for a dominantly inherited nemaline myopathy with core-like lesions. Brain 2003;126:1545-51.

14 Wallgren-Pettersson C, Laing NG. 109th ENMC International Workshop: 5th workshop on nemaline myopathy, 11 th-13th October 2002, Naarden, The Netherlands. Neuromuscul Disord 2003;13:501-7.

15 Stojkovic T, Maurage CA, Moerman A, Hurtevent JF, Krivosic-Horber R, Pellissier JF, Vermersch P. Congenital myopathy with central cores and fingerprint bodies in association with malignant hyperthermia susceptibility. Neuromuscul Disord 2001;11:538-41.

16 Sparrow JC, Nowak KJ, Durling HJ, Beggs AH, Wallgren-Pettersson C, Romero N, Nonaka I, Laing NG. Muscle disease caused by mutations in the skeletal muscle alpha-actin gene (ACTA1). Neuromuscul Disord 2003;13:519-31.

17 De Cauwer H, Heytens L, Martin JJ. Workshop report of the 89th ENMC International Workshop: Central Core Disease, 19th-20th January 2001, Hilversum, The Netherlands. Neuromuscul Disord 2002;12:588-95.

18 Schuelke $M$. An economic method for the fluorescent labeling of PCR fragments. Nat Biotechnol 2000;18:233-4.

19 Kennedy GC, Matsuzaki H, Dong S, Liu WM, Huang J, Liu G, Su X, Cao M, Chen W, Zhang J, Liu W, Yang G, Di X, Ryder T, He Z, Surti U, Phillips MS, Boyce-Jacino MT, Fodor SP, Jones KW. Large-scale genotyping of complex DNA. Nat Biotechnol 2003;21:1233-7.

20 Abecasis GR, Cherny SS, Cookson WO, Cardon LR. GRR: graphical representation of relationship errors. Bioinformatics 2001;17:742-3.

21 O'Connell JR, Weeks DE. PedCheck: a program for identification of genotype incompatibilities in linkage analysis. Am J Hum Genet 1998;63:259-66.

22 Abecasis GR, Cherny SS, Cookson WO, Cardon LR. Merlin-rapid analysis of dense genetic maps using sparse gene flow trees. Nat Genet 2002;30:97-101.

23 Strauch K, Fimmers R, Kurz T, Deichmann KA, Wienker TF, Baur MP. Parametric and nonparametric multipoint linkage analysis with imprinting and two-locus-trait models: application to mite sensitization. Am J Hum Genet 2000;66:1945-57.

24 Kruglyak L, Daly MJ, Reeve-Daly MP, Lander ES. Parametric and nonparametric linkage analysis: a unified multipoint approach. Am J Hum Genet 1996;58:1347-63.

25 Vandekerckhove J, Bugaisky G, Buckingham M. Simultaneous expression of skeletal muscle and heart actin proteins in various striated muscle tissues and cells. A quantitative determination of the two actin isoforms. J Biol Chem 1986;261:1838-43

26 Olson TM, Michels VV, Thibodeau SN, Tai YS, Keating MT. Actin mutations in dilated cardiomyopathy, a heritable form of heart failure. Science 1998;280:750-2.

27 Mogensen J, Klausen IC, Pedersen AK, Egeblad H, Bross P, Kruse TA, Gregersen N, Hansen PS, Baandrup U, Borglum AD. Alpha-cardiac actin is a novel disease gene in familial hypertrophic cardiomyopathy. J Clin Invest 1999:103:39-43.

28 Sheff DR, Rubenstein PA. Amino-terminal processing of actins mutagenized at the Cys-1 residue. J Biol Chem 1992;267:2671-8.

29 Walker KW, Bradshaw RA. Yeast methionine aminopeptidase I. Alteration of substrate specificity by site-directed mutagenesis. J Biol Chem 1999;274:13403-9.

30 Tsunasawa S, Stewart JW, Sherman F. Amino-terminal processing of mutant forms of yeast iso-1-cytochrome $c$. The specificities of methionine aminopeptidase and acetyltransferase. J Biol Chem 1985;260:5382-91.

31 Cook RK, Root D, Miller C, Reisler E, Rubenstein PA. Enhanced stimulation of myosin subfragment 1 ATPase activity by addition of negatively charged residues to the yeast actin NH2 terminus. J Biol Chem 1993;268:2410-5.

32 Brenner B, Kraft T, DasGupta G, Reisler E. Cross-bridge binding to actin and force generation in skinned fibers of the rabbit psoas muscle in the presence of antibody fragments against the $\mathrm{N}$-terminus of actin. Biophys $J$ 1996;70:48-56.

33 Sutoh K, Hatano S. Actin-fragmin interactions as revealed by chemical crosslinking. Biochemistry 1986;25:435-40.

34 Martin DJ, Rubenstein PA. Alternate pathways for removal of the class II actin initiator methionine. J Biol Chem 1987;262:6350-6.

35 Hinz B, Gabbiani G, Chaponnier C. The NH2-terminal peptide of alphasmooth muscle actin inhibits force generation by the myofibroblast in vitro and in vivo. J Cell Biol 2002;157:657-63

36 Sutoh K, Ando M, Sutoh K, Toyoshima YY. Site-directed mutations of Dictyostelium actin: disruption of a negative charge cluster at the $\mathrm{N}$ terminus. Proc Natl Acad Sci U S A 1991;88:7711-4. 